\title{
POEMS syndrome associated with multiple hemangiomas of the small bowel and colon
}

POEMS is an acronym for polyneuropathy, organomegaly, endocrinopathy, monoclonal gammopathy, and skin changes. POEMS syndrome is a rare disorder, with only a limited number of cases reported in the literature. The first descriptions of POEMS syndrome were published by Crow in 1956 [1] and by Fukase in 1968 [2]. It is therefore also known as Crow-Fukase syndrome. The symptom complex of POEMS syndrome includes skin changes such as hyperpigmentation, skin thickening, sclerodermoid changes, hypertrichosis, and hemangiomas [3]. Glomeruloid hemangiomas of the skin are thought to be specific to POEMS syndrome and have been shown to affect one-third of patients [4].

A 59-year-old white man with known POEMS syndrome was admitted to our department. At the time of admission, he presented with gastrointestinal bleeding, melena, and general weakness. His hemoglobin concentration had dropped from $11.0 \mathrm{~g} / \mathrm{dL}$ to $8.5 \mathrm{~g} / \mathrm{dL}$.

The patient had received effective anticoagulation treatment with warfarin for permanent atrial fibrillation. Esophagogastroduodenoscopy did not reveal relevant pathologic findings. Colonoscopy (CF-H180AI/L; Olympus Corp., Tokyo, Japan) showed multiple hemangiomas 5 $10 \mathrm{~mm}$ in diameter scattered over the entire colonic mucosa ( $\bullet$ Fig. 1 ). In addition, multiple polypoid hemangiomas of the mucosa of the jejunum and ileum were detected by small-bowel videocapsule endoscopy (PillCam SB; Given Imaging Ltd., Yoqneam, Israel) ( Video 1).

This is the first report of a patient with POEMS syndrome in whom multiple mucosal hemangiomas of the small bowel and colon were found. We conclude that hemangiomas in POEMS syndrome are not only limited to the skin but may also occur in the gastrointestinal tract. This observation should be taken into account for future diagnostic measures in patients with suspected POEMS syndrome, especially those patients at high risk of gastrointestinal bleeding.

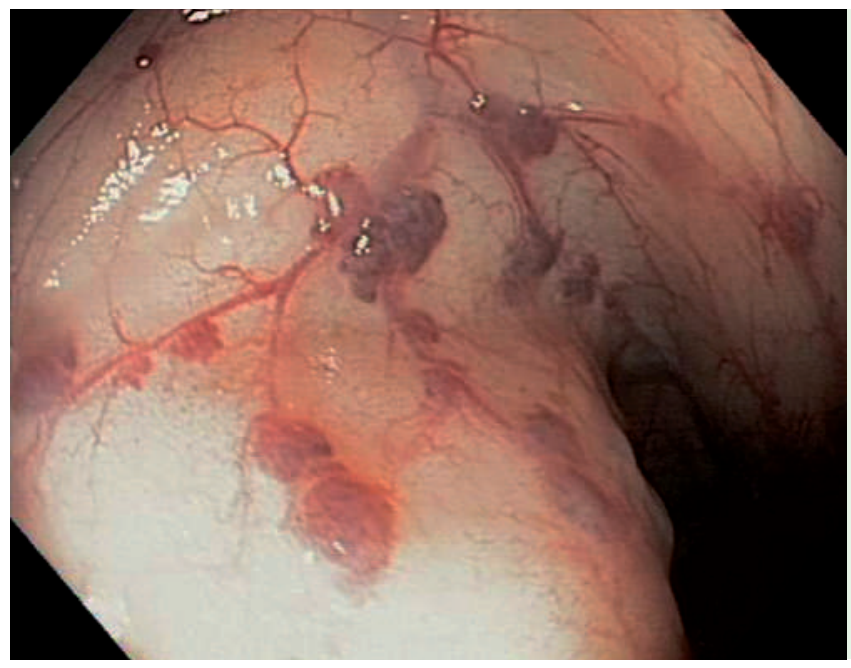

Fig. 1 Colonoscopy revealed multiple hemangiomas spread over the entire colonic mucosa. As seen here, the hemangiomas have a botryoid distribution with typical feeding vessels. This picture is taken from the sigmoid region.

\section{Video 1}

Video sequence of the mid-jejunum taken by videocapsule endoscopy shows multiple hemangiomas - some of them in a polypoid pattern.

Endoscopy_UCTN_Code_CCL_1AD_2AF

\section{T. Meister, H. Heinzow, F. Lenze,}

H. Ullerich, W. Domschke, D. Domagk

Department of Medicine B, Westfälische

Wilhelms-Universität, Münster, Germany

\section{References}

1 Crow RS. Peripheral neuritis in myelomatosis. Br Med J 1956; 2: 802-804

2 Nakanishi T, Sobue I, Toyokura Y et al. The Crow-Fukase syndrome: study of 102 cases in Japan. Neurology 1984; 34: 712 - 720

3 Dispenzieri A, Kyle RA, Lacy MQ et al. POEMS syndrome: definitions and long-term outcome. Blood 2003; 101: $2496-2506$

4 Tsai CY, Lai CH, Chan HL, Kuo TT. Glomeruloid hemangioma - a specific cutaneous lesion of multicentric Castleman's disease associated with POEMS syndrome. Int J Dermatol 2001; 40: 401 - 414
Bibliography

DoI 10.1055/s-2007-995686

Endoscopy 2008; 40: E134

(c) Georg Thieme Verlag KG Stuttgart · New York ISSN 0013-726X

Corresponding author

\section{T. Meister, MD}

Department of Medicine B

Westfälische Wilhelms-Universität

Albert-Schweitzer-Str. 33

48129 Münster

Germany

Fax: + 49-251-8356186

Tobias.Meister@ukmuenster.de 